\title{
A Case of Possible Loiasis Contracted in Cameroon and Diagnosed in Milan, Italy, and Review of Cases Published in Dermatological Journals
}

\author{
Luisa Lunardon Maurizio Romagnuolo Marco Cusini Stefano Veraldi \\ Department of Pathophysiology and Transplantation, Università degli Studi, Foundation \\ IRCCS Ca' Granda Ospedale Maggiore Policlinico, Milan, Italy
}

\section{Keywords}

Loa loa $\cdot$ Loiasis $\cdot$ Calabar swellings · Diethylcarbamazine $\cdot$ Ivermectin · Albendazole

\begin{abstract}
Loiasis is an infestation of the skin and eyes caused by the nematode Loa loa. We report a case of loiasis in a woman who contracted the infestation in Cameroon. The clinical picture was characterized by Calabar swellings on the upper limbs and axillary lymphadenopathy. Laboratory tests revealed persistent leucocytosis with neutropenia, lymphopenia, and eosinophilia. The search for microfilariae was always negative. The patient was successfully treated with ivermectin and albendazole. Follow-up (5 years) was negative for both clinical manifestations and laboratory tests.
\end{abstract}

\section{Introduction}

Loiasis is an infestation of the skin and eyes caused by the nematode Loa loa. Vectors of the disease are flies of the genus Chrysops ("red fly"). A small number of articles on loiasis in dermatological journals have been published [1-21]. This disease should be known by dermatologists in consideration of the increase of immigrants from poor countries, and tourists who visit tropical and subtropical countries.

We present a case of possible loiasis in a woman who contracted the infestation in Cameroon, where loiasis is endemic. A review of the literature published in dermatological journals is included. 
Fig. 1. Mildly erythematous Calabar swelling.

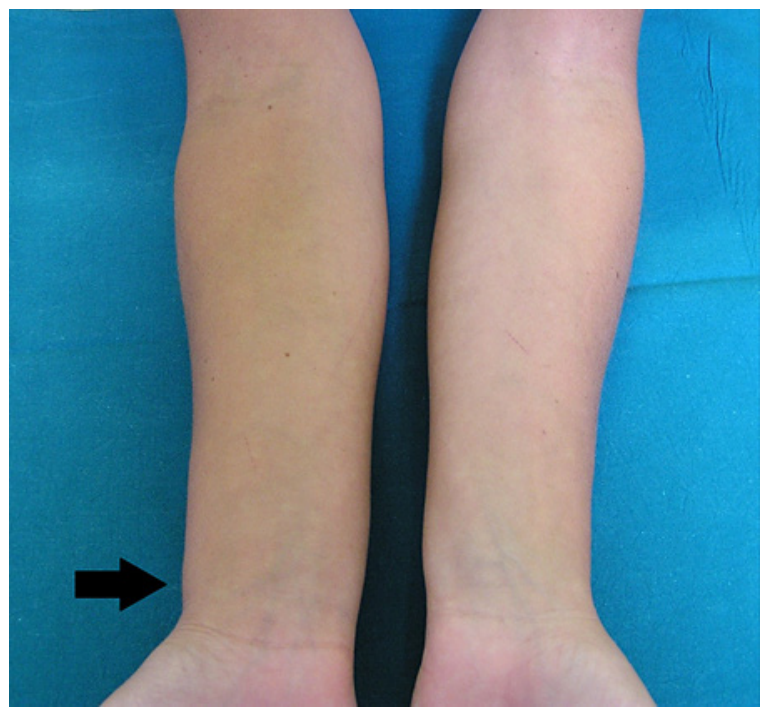

\section{Case Presentation}

A 42-year-old Caucasian woman was admitted to our Dermatology Unit in January 2014 because of transient cutaneous itchy swellings and axillary lymphadenopathy of the right upper limb. The patient stated that she visited Cameroon in 2012 and February 2013. In particular, she visited the cities of Yaoundé and Douala, the region of the Northwest, inhabited by the Fang ethnicity, and the central region, inhabited by the Eton ethnicity. The patient also declared that lymphoedema and axillary lymphadenopathy appeared in May 2013. The patient was subjected at other centres to laboratory tests that revealed leucocytosis (13.500 leucocytes $/ \mathrm{mm}^{3}$ ), with lymphopenia (1.700 lymphocytes $/ \mathrm{mm}^{3}$ [12.7\%]) and eosinophilia (4.800 eosinophils $/ \mathrm{mm}^{3}$ [35.8\%]) (July 2013). In the same month, the patient was subjected to ultrasound of axillae that revealed right lymphadenitis. The search for blood microfilariae was negative. In Table 1, the evolution of leucocytes from July 2013 to September 2015 is reported. When the patient was admitted to our Dermatology Unit (January 2014), dermatological examination revealed a mildly erythematous swelling of soft-parenchymatous consistency, $8 \mathrm{~cm}$ in size, on the right upper limb (Fig. 1). It lasted $2-4 \mathrm{~h}$ and was accompanied by pruritus and burning sensation. A clinical diagnosis of Calabar swelling was made. The search for microfilariae was negative at 12:00 a.m. as well as at 12:00 p.m. In July 2014, immunochromatographic test for Loa loa and Wuchereria bancrofti was negative. In March 2015, the search for Loa loa microfilariae was negative. In May 2015, serology for Loa loa and Wuchereria bancrofti was negative. The patient finally accepted to be treated with ivermectin $(200 \mathrm{mcg} / \mathrm{kg} /$ week for 3 weeks), albendazole ( $800 \mathrm{mg} /$ day for 1 month) and cetirizine (10 mg/day) (she was concerned about side effects of diethylcarbamazine because of past herpetic encephalitis). No side effects were reported or observed, except mild widespread pruritus. In this patient, the absence of side effects caused by ivermectin was very probably due to the persistent negativity of microfilaremia [22].

Twenty days later, Calabar swellings disappeared and a significant decrease in leucocytes and eosinophils was detected. Furthermore, neutrophils and lymphocytes returned to normal values (Table 1). Follow-up (5 years) was negative for both clinical manifestations and laboratory tests. 
Table 1. White blood cells, lymphocytes, and eosinophils

\begin{tabular}{lllll}
\hline Date, month, year & WBCs $/ \mathrm{mm}^{3}$ & Neutrophils, \% & Lymphocytes, \% & Eosinophils $/ \mathrm{mm}^{3}(\%)$ \\
\hline July 2013 & 13.500 & 46.5 & 12.7 & $4.800(35.8)$ \\
July 2013 & 13.400 & 41.7 & 14.1 & $5.300(40)$ \\
September 2013 & 16.800 & 34.2 & 11.9 & $8.300(49.7)$ \\
November 2013 & 15.400 & 24.2 & 12.9 & $9.100(59.3)$ \\
January 2014 & 17.800 & 25.5 & 14.6 & $9.400(52.6)$ \\
March 2014 & 22.000 & 19.6 & 10.2 & $14.800(67.3)$ \\
April 2014 & 19.100 & 21.2 & 8.9 & $12.700(66.7)$ \\
May 2014 & 18.800 & 17.7 & 12 & $12.200(65.1)$ \\
September 2014 & 16.200 & 30.5 & 11.2 & $8.500(52.6)$ \\
November 2014 & 18.300 & 46.2 & 9 & $7.400(40.3)$ \\
May 2015 & 10.300 & 32.7 & 13.2 & $5.200(50.3)$ \\
May 2015: beginning of the therapy with albendazole and ivermectin & \\
July 2015 & 7.300 & 56.8 & 24.5 & $800(11)$ \\
September 2015 & 6.900 & 60 & 23.3 & $640(9.2)$ \\
\hline
\end{tabular}

\section{Discussion}

The male of Loa loa is $3 \mathrm{~cm}$ long, with a diameter of $0.4-0.5 \mathrm{~mm}$; the female is $5-7 \mathrm{~cm}$ long, with the same diameter [9]. Loa loa infects only humans and primates. It can survive more than 20 years. Adult worms live in the dermis; however, they move actively. Microfilariae, released by adult females, migrate from connective tissue to peripheral blood, with a peak at 12:00 a.m.: loiasis has a diurnal periodicity $[9,11]$. Vectors of the disease are female flies of the genus Chrysops ("red fly"). Natural habitat is forests and swamps of Western and Central Equatorial Africa $[9,14,21]$. The highest diffusion of these insects is during rainy seasons [20].

Larvae penetrate the skin through the stings of flies; subsequently, they reach the dermis and mature very slowly: complete development to adult worm requires $>1$ year. The incubation period of loiasis ranges from 3 to 15 months, but it can also last up to 3-4 years.

On the skin, loiasis is characterized by typical swellings, the so-called Calabar swellings, from the name of a Nigerian city where loiasis is endemic. Calabar swellings occur in $50 \%$ of patients [20]. They appear suddenly, especially on the limbs; however, they can involve other skin areas, such as the face [7]. They are $5-20 \mathrm{~cm}$ in size, are more or less erythematous, and accompanied by pruritus and/or burning sensation. Calabar swellings are transitory, with a duration from a few hours to $2-4$ days, and migratory, with a chronic-recurrent clinical course $[5,9,14,21]$. Calabar swellings are accompanied by increased blood eosinophilia and inflammatory tests. The adult worm may sometimes appear as a thin palpable track on the skin $[6,16]$ that moves quickly; not rarely, the patient complains of a feeling of movements beneath the skin $[9,12,13]$. Very rarely the worm extrudes spontaneously from the skin. Calabar swellings may be accompanied by acute/chronic urticaria and angioedema [9]. Other skin manifestations of loiasis are foreign body granulomas and worm calcification [10].

Ocular involvement occurs in $70 \%$ of patients [20]: it is due to the passage of adult worms in the orbital space, anterior room, and conjunctivas $[4,7,9-11,13,14,20]$. Clinical manifestations are eyelid edema, blepharoconjunctivitis (with increase of lachrymation and photophobia), posterior uveitis, chorioretinitis, and optical neuritis [9]. 
Systemic manifestations are uncommon; they are asthenia [14, 21], fever [14, 21], headache, meningoencephalitis (with psychiatric symptoms, such as depression and insomnia) [9], peripheral neuropathy [1, 9], pneumonia, myocardial fibrosis [9], glomerulonephritis [9, 14], lymphadenitis [9], and hydrocele. Arthralgia and arthritis [9], especially on the knees, are rather common and are due to the deposition of immune complexes or the presence of microfilariae in the synovial fluid. Natives of endemic areas are often asymptomatic [20]. Laboratory tests show marked blood eosinophilia $[9,11,13,20,21]$ and increase in inflammatory tests and total IgE [9].

Diagnosis is based on epidemiological, anamnestic, clinical, and laboratory data. Definitive diagnosis is established by blood samples collected at 12:00 a.m. because of the diurnal periodicity of microfilariae $[5,11,12,15,20]$. The female of Loa loa irregularly releases microfilariae in the peripheral blood: blood samples have to be collected in different days. The search for microfilariae is not always positive in all patients: in the article by Davis, microfilariae were detected in 3 out of 20 patients [9]. In a group of 26 Moroccan patients who were infected in Equatorial Guinea, microfilaremia was present in 8 out of 26 patients [14]. Negative search for microfilariae is therefore common in non-native patients $[9,14]$. Identification of Loa loa microfilariae is based on morphological features (presence/absence of the sheath, location of nuclei, morphology of cephalic and terminal portions) [12]. Adult Loa loa may be extracted from the skin $[6,8,12,13,20]$ or conjunctivas $[4,20]$. When isolation of microfilariae is negative, but medical history and clinical features are consistent with a diagnosis of loiasis, the observation of Calabar swellings is considered a typical feature of the disease [5], although they may be observed also in Mansonella perstans infestation. In our patient, the diagnosis of loiasis was based on: (a) history of multiple travels to an endemic area for loiasis; (b) the presence of chronic-recurrent Calabar swellings on an upper limb; (c) persistent leukocytosis, neutropenia, lymphopenia and marked eosinophilia; (d) rapid clinical remission and negativity of laboratory tests following specific therapy; and (e) very long and negative follow-up.

The therapy is based on diethylcarbamazine $[7-9,11,13,14,20]$. Albendazole and ivermectin are second line therapy $[11,14,20,21]$. The therapy is also based, when possible, on the surgical extraction of adult worms from the skin $[12,13]$ and conjunctivas [4]. Prophylaxis consists of skin protection with repellents [9].

Although loiasis is of very rare observation in Western countries, it should be known by dermatologists in consideration of the increase of immigrants from poor countries, and tourists who visit tropical and subtropical countries.

\section{Statement of Ethics}

The patient provided written consent to publish her case (including images). Measures were taken to maintain the privacy of the patient. This research was conducted ethically in accordance with the World Medical Association Declaration of Helsinki.

\section{Conflict of Interest Statement}

The authors have no conflicts of interest to disclose.

\section{Funding Sources}

The authors did not receive any funding.

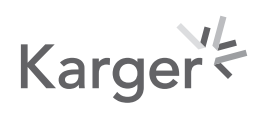




\section{Author Contributions}

All the authors equally contributed to the manuscript, including drafting, revising, and interpretation.

\section{References}

1 Sarkany I. Loaiasis with involvement of peripheral nerves. Trans St Johns Hosp Dermatol Soc. 1959;42:49-51. Rivoire J, Castel J, Despeignes J, Battesti MR. [A case of Loa loa filariasis]. Lyon Med. 1965;214:211-2.

3 Cristofolini M, Pedrazzoli M. Aspetti dermatologici della loaiasi. Giorn Ital Derm. 1967;108:411-8.

4 Hubler WR Jr, Gregory JF, Knox JM, Falls H. Loaiasis. A case report and review of the literature. Arch Dermatol. 1973;108:835-6.

5 Grasa Jordán P, Marrón Gasca J, Gómez Lus R, Rubio Calvo C, Navarro Lucia M. Filariasis por Loa loa (loaiasis). Actas Dermosifiliogr. 1979;70:467-74.

6 Vermeer BJ, van der Kaay HJ. Loiasis: a case report. Acta Derm Venereol. 1982;62:78-9.

7 Marriott WRV. Loiasis. Int J Dermatol. 1985;24(5):329-32.

8 Marriott WRV. Loiasis in a young child in Oregon. Int J Dermatol. 1986;25:252-4.

9 Davis BR. Filariases. Dermatol Clin. 1989;7(2):313-22.

10 Le Guyadec T, Wolkenstein P, Ortoli JC, Ponties-Leroux B, Beaulieu P, Millet P. Granulome à corps étranger sur filaire Loa loa calcifiée. Ann Dermatol Venereol. 1992;119:127-30.

11 Osumalia-Soendjojo N, Prens EP, Sluiters JF, Naafs B. Psoriasis and filariasis. Br J Dermatol. 1994;131:723-4.

12 de Viragh PA, Guggisberg D, Derighetti M, van Saanen, Panizzon RG. Monosymptomatic Loa loa infection. Dermatology. 1998;197:303-5.

13 James WD. Imported skin diseases in dermatology. J Dermatol. 2001;28(11):663-6.

14 El Haouri M, Erragragui Y, Sbai M, Alioua Z, Louzi, El Mellouki W, Sedrati O. Filariose cutanée à Loa loa. 26 cas marocains d'importation. Ann Dermatol Venereol. 2001;128:899-902.

15 Morrone A, Franco G, Toma L, Tchangmena OB, Marangi M. A case of loiasis in Rome. J Eur Acad Dermatol Venereol. 2002;16:280-3.

16 Darie H, Etzol S, Ortoli JC. Les dermatites rampantes d'importation relèvent de diverses étiologie. Nouv Dermatol. 2004;23:132-3.

17 Fischer M, Reinel D. Urlaubs- und tropendermatosen. Hautarzt. 2012;63(5):396-405.

18 Oninla OA, Onayemi O. Skin infections and infestations in prison inmates. Int J Dermatol. 2012;51:178-81.

19 Vanhaecke C, Perignon A, Monsel G, Regnier S, Paris L, Caumes E. Aetiologies of creeping eruption: 78 cases. Br J Dermatol. 2014;170:1166-9.

20 Lupi O, Downing C, Lee M, Pino L, Bravo F, Giglio P, et al. Mucocutaneous manifestations of helminth infections: nematodes. J Am Acad Dermatol. 2015;73:929-6.

21 Ouédraogo NA, Korsaga-Somé N, Traoré F, Kaboret N, Zida A, Tapsoba GP, et al. Loa loa filariasis in a tropical savanna area: report of one case in Ouagadougou. Int J Dermatol. 2020;59:482-3.

22 Kamgno J, Pion SD, Mackenzie CD, Thylefors B, Boussinesq M. Loa loa microfilarial periodicity in ivermectintreated patients: comparison between those developing and those free of serious adverse events. Am J Trop Med Hyg. 2009;81:1056-61. 